\title{
Aplikasi Penggajian Karyawan Pada CV System Comutama
}

\author{
Вауи Kusumo \\ Program Studi Informatika Universitas Indraprasta PGRI Jakarta, Jln. Raya Tengah Gedong, Jakarta Timur, 13760, Indonesia \\ bayukusumo123@gmail.com
}

INFORMASI ARTIKEL

Sejarah Artikel:

Diterima Redaksi: 25-01-2020

Revisi Akhir: 19-09-2020

Diterbitkan Online: 22-10-2020

\section{KATA KUNCI}

\begin{tabular}{l} 
Aplikasi \\
Penggajian \\
Java \\
MySQL \\
KORESPONDENSI \\
\hline Telepon:081286540065 \\
E-mail: bayukusumo123@gmail.com
\end{tabular}

\section{A B S T R A C T}

CV System Comutama is a business entity engaged in the sale of computer accessories. The payroll system contained in the CV System Comutama has not been carried out to the full potential for it requires a payroll application that can support the delivery of data more effectively and efficiently. The purpose of this research is to design employee payroll applications on the CV System Comutama effectively and efficiently, facilitate the financial department to be able to calculate employee payroll quickly and minimize errors and to facilitate the achievement of reports that are fast, accurate, valid, effective and efficient. The research method used is the grounded research method to collect data and analyze data at the same time. The modeling system used is the Data Flow Diagram (DFD) method using the java programming language while the database uses MySQL. With the employee payroll application is expected to facilitate the calculation of employee salaries and provide employee salary data reports that are stored neatly, safely, and accurately in a database that is systematic.

\section{PENDAHULUAN}

Perkembangan dunia teknologi berlangsung cepat dengan hadirnya bermacam-macam perangkat keras dan perangkat lunak yang lebih baik dari sebelumnya. Pesatnya perkembangan teknologi, maka tidaklah heran jika di berbagai perusahaan, instansi atau organisasi banyak yang menggunakan komputer sebagai alat bantu yang mampu menyimpan dan mengolah segala macam data dengan cepat, tepat dan akurat.

Manajemen Sumber Daya Manusia dalam proses kompensasi (dijabarkan dalam kebijakan penggajian terhadap karyawan) berperan sangat penting dalam rangka meningkatkan kinerja karyawan suatu organisasi, baik organisasi yang profit oriented maupun organisasi nirlaba. Ketidakcakapan manajemen dalam mengelola sumber daya manusianya bisa menyebabkan ketidakharmonisan hubungan karyawan dan manajemen organisasi tersebut. Apabila hal ini tersebut terus berlanjut tanpa ada penanganan yang baik, akan mengakibatkan turunnya motivasi kerja para karyawan, sehingga dapat berpengaruh terhadap kinerja organisasi [1].

Pembayaran atau penyerahan jasa yang dilakukan oleh karyawan yang mempunyai jenjang jabatan manajer, sedangkan upah umumnya merupakan pembayaran atas penyerahan jasa yang dilakukan oleh karyawan pelaksana (buruh). Umunya gaji dibayarkan secara tetap bulan, sedangkan upah dibayarkan berdasarkan hari kerja, jam kerja atau jumlah satuan produk yang dihasilkan". Berdasarkan definisi di atas, dapat diambil kesimpulan bahwa gaji merupakan pembayaran atau penyerahan jasa dari perusahaan kepada karyawannya dan umumnya tarif gaji biasanya dinyatakan dalam gaji perbulan [2].

Fungsi gaji bukan hanya membantu manajer personalia dalam menentukan gaji yang adil dan layak saja, tetapi masih ada fungsi-fungsi yang lain, yaitu untuk menarik pekerja yang mempunyai kemampuan kedalam organisasi, untuk mendorong pekerja agar menunjukkan prestasi yang tinggi dan untuk memelihara prestasi pekerja selama periode yang panjang [3]. Kegunaan dari adanya prosedur pembayaran gaji pegawai adalah untuk memfasilitasi pertukaran dana antara pegawai dengan jasa yang dibutuhkan.

Sebenarnya penerapan sistem penggajian di CV. System Comutama sebenarnya sudah baik. Karena jumlah pegawainya pun belum terlalu banyak. Tetapi bayangkan jika setiap tahun jumlahnya bertambah, maka tidak mungkin jika terus dilakukan secara manual. Banyak kendala dan hambatan yang bisa terjadi. Tidak menutup kemungkinan terjadi kesalahan ketika pegawai yang bertugas mengurus penggajian melakukan kesalahan dalam penghitungan. 
Dengan adanya sistem yang terkomputerisasi diharapkan dapat meningkatkan efisiensi kerja, kecepatan dan ketepatan dalam suatu pengambilan keputusan. Dalam upaya mencegah kecurangan-kecurangan yang mungkin terjadi terhadap penggajian kepada para tenaga kerja maka diperlukan adanya sistem informasi penggajian, dimana terdapat formulir-formulir, catatan-catatan dan prosedurprosedur yang digunakan untuk menetapkan gaji yang harus diberikan kepada para tenaga kerja. Untuk menjamin kelangsungan dan kesungguhan para tenaga kerja dalam melaksanakan tugasnya pihak manajemen dituntut agar menentukan gaji yang sesuai dengan keahlian, jabatan, pendidikan, masa kerja, pengalaman, kondisi perusahaan, upah minimum regional (UMR) serta pengaturan penggajian yang ditetapkan oleh pemerintah sesuai dengan UUD [4].

\section{TINJAUAN PUSTAKA}

\subsection{Pengertian Sistem}

Sistem adalah kumpulan dari dua atau lebih komponen yang saling bekerja dan berhubungan untuk mencapai tujuan tertentu. Dia juga berpenapat bahwa perusaahan adalah sebuah sistem yang terdiri dari beberapa departremen yang bertindak sebagai susbsitem yang membentuk sistem perusahaan tersebut. Sedangkan pendapat lain mengatakan sistem adalah suatu jaringan kerja dari proosedur-prosedur yang saling berhubungan, berkumpul bersama- sama untuk melakukan suatu kegiatan atau untuk meyelesaikan suatu sasaran tertentu [5].

\subsection{Aplikasi}

Secara istilah pengertian aplikasi adalah suatu program yang siap untuk digunakan yang dibuat untuk melaksanankan suatu fungsi bagi pengguna jasa aplikasi serta penggunaan aplikasi lain yang dapat digunakan oleh suatu sasaran yang akan dituju. Menurut kamus computer eksekutif, aplikasi mempunyai arti yaitu pemecahan masalah yang menggunakan salah satu tehnik pemrosesan data aplikasi yang biasanya berpacu pada sebuah komputansi yang diinginkan atau diharapkan maupun pemrosesan data yang di harapkan [6].

\subsection{Data Flow Diagram (DFD)}

DFD memperlihatkan gambaran tentang masukanproses-keluaran dari suatu sistem/perangkat lunak, yaitu obyek-obyek data mengalir ke dalam perangkat lunak, kemudian ditransformasi oleh elemen-elemen pemrosesan dan obyek-obyek data hasilnya akan mengalir keluar dari sistem/perangkat lunak [7].

Langkah-langkah dalam membuat data flow diagram dibagi menjadi tiga, diagram konteks, diagram nol, dan diagram rinci.

1) Diagram Konteks

Diagram ini dibuat untuk menggambarkan sumber serta tujuan data yang akan diproses atau dengan kata lain diagram tersebut digunakan untuk menggambarkan sistem secara umum/global dari keseluruhan sistem yang ada.

2) Diagram Nol

Diagram ini dibuat untuk menggambarkan tahapan proses yang ada didalam diagram konteks, yang penjabarannya lebih terperinci.
3) Diagram Rinci

Diagram ini dibuat untuk menggambarkan arus data secara lebih mendetail lagi dari tahapan proses yang ada didalam diagram nol.

\section{METODOLOGI}

Penelitian ini menggunakan metode grounded research yang bertujuan untuk mengetahui proses perancangan sistem penggajian karyawan pada CV System Comutama yang dilakukan selama ini. Grounded Research adalah sebuah metodologi penelitian kualitatif yang menekankan penemuan teori dari data observasi empirik di lapangan dengan metode induktif (menemukan teori dari sejumlah data), generatif yaitu penemuan atau konstrukti teori menggunakan data sebagai evidensi, konstruktif menemukan konstruksi teori atau kategori lewat analisis dan proses mengabstraksi, dan subjektif, yaitu merekonstruksi penafsiran dan pemaknaan hasil penelitian berdasarkan konseptualisasi masyarakat yang dijadikan subjek studi [8]. Dengan metode ini, penulis melakukan pengumpulan data dan analis data dalam waktu yang bersamaan. Sehingga perancangan sistem penggajian karyawan pada CV System Comutama yang dibuat berdasarkan fakta yang ada di lapangan. Data yang dikumpulkan sesuai dengan kebutuhan sistem yang akan dirancang.

\subsection{Metode Pengembangan Sistem}

Langkah penyelesaian masalah pada perancangan sistem aplikasi penggajian karyawan pada CV. System Comutama, yaitu dengan menggunakan model proses atau paradigm waterfall.

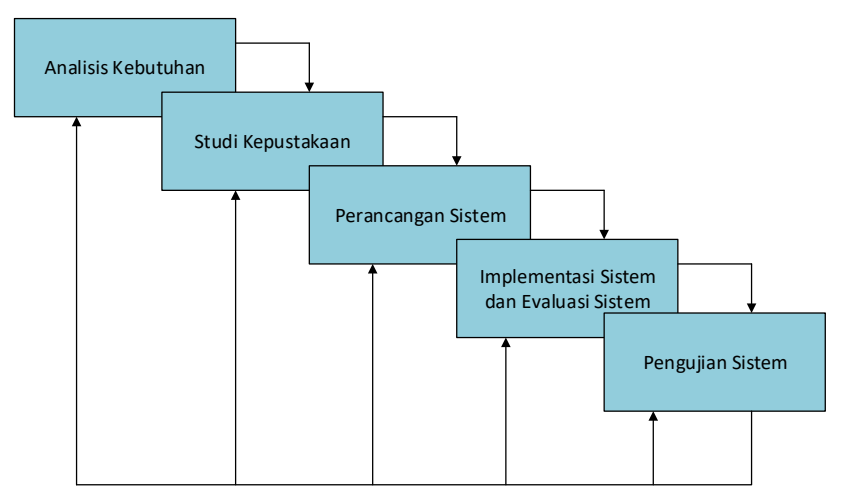

Gambar 1. Metode Pengembangan Sistem Waterfall

Adapun langkah-langkah yang dilakukan dalam proses pengembangan system dengan metode waterfall model adalah sebagai berikut:

a) Analisis kebutuhan

Analisa kebutuhan berguna untuk mendapatkan datadata yang akan digunakan sebagai masukkan dari suatu sistem dan untuk memperoleh data yang berhubungan dengan tugas akhir ini. Proses perancangan sistem aplikasi penggajian karyawan pada CV. System Comutama dimulai dari memahami pengguna.

b) Studi kepustakaan

Penulis melakukan studi kepustakaan berdasarkan referensi dan berbagai diskusi pembahasan baik dengan dosen pembimbing maupun dengan orang yang berkompeten pada kasus ini. Studi kepustakaan 
bertujuan untuk mempelajari dan memahami dasar teori yang berhubungan dengan analisa kebutuhan yang telah dilakukan. Selain itu, penulis juga melakukan studi dari berbagai media yang berupa diktat, modul, buku-buku, artikel-artikel baik di internet maupun media cetak untuk menunjang demi terselesaikannya tugas akhir ini.

c) Perancangan sistem

Perancangan sistem bertujuan untuk merancang sistem aplikasi penggajian karyawan pada CV System Comutama agar dapat diimplementasikan dengan kebutuhan pengguna.

d) Implementasi sistem dan evaluasi sistem

Suatu proses menterjemahkan dokumen hasil desain menjadi baris-baris perintah bahasa pemrograman komputer. Semakin baik hasil analisa dan desain yang dilakukan, maka proses pengkodean ini akan lebih mudah dilakukan. Sedangkan evaluasi yang ditujukan sebagai bagian dari tahap terakhir perancangan sistem biasanya dimaksudkan untuk pembahasan. Bila ditemukan suatu masalah maka akan kembali ke tahap sebelumnya dan memodifikasinya.

e) Pengujian sistem

Sebelum sistem aplikasi dapat digunakan, maka harus dilakukan pengujian telebih dahulu. Pengujian dilakukan untuk memastikan apakah semua fungsi sistem aplikasi bekerja dengan baik. Rangkaian pengujian ini sangat penting dilakukan untuk menjamin kualitas software, dan juga menjadi peninjauan terakhir terhadap spesifikasi, desain dan pengkodean dari sistem yang telah ada atau sistem yang sedang berjalan.

\section{HASIL DAN PEMBAHASAN}

\subsection{Rancangan Sistem}

Rancangan sistem yang digunakan bahasa pemodelan metode Data Flow Diagram (DFD) atau dalam bahasa Indonesia menjadi Diagram Alir Data (DAD). DFD yang digunakan dalam rancangan sistem ini adalah:

1) Diagram konteks sistem berjalan

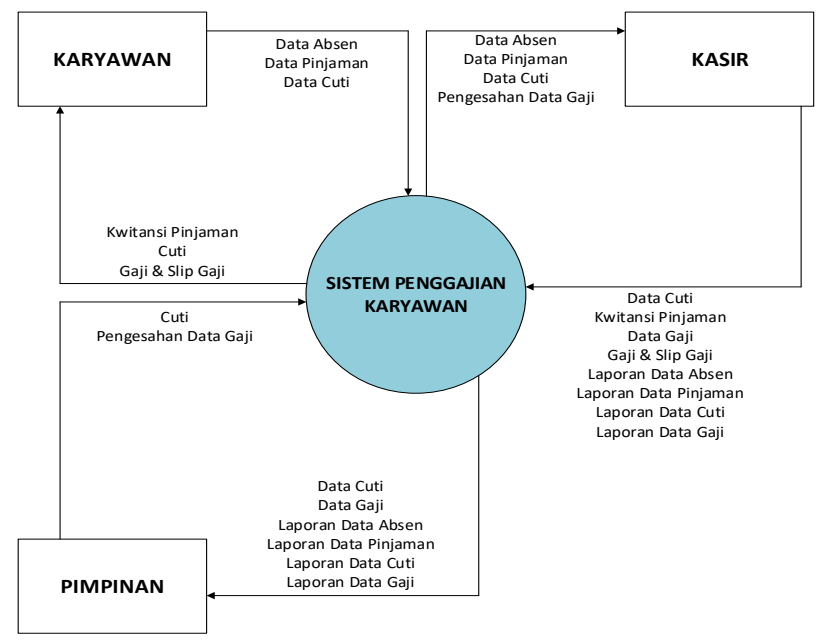

Gambar 2. Diagram konteks sistem berjalan

Dari hasil yang penulis lakukan, maka penulis dapat menganalisis permasalahan yang ada pada CV. System Comutama, yaitu: a. Proses pendataan karyawan, pendataan potongan, pendataan cuti dan pendataan gaji masih dilakukan secara manual dengan menggunakan media kertas atau buku besar, sehingga kemungkinan terjadi kehilangan data.

b. Proses penghtungan penggajian pada CV. System Comutama menggunakan microsoft excel dan untuk pendataannya masih dilakukan secara manual, sehingga dalam perhitungan masih lamban dan memungkinkan adanya kesalahan-kesalahan yang terjadi karena kurang teliti dan kurang efisien.

c. Pembuatan laporannya pada setiap bulannya masih dilakukan secara manual, pembuatan laporan menjadi kurang akurat dan tidak tepat waktu, banyak pencatatan yang salah dan harus dilakukan ulang.

Berdasarkan masalah-masalah yang dihadapi, maka alternatif penyelesaian masalahnya, yaitu:

a. Sistem aplikasi penggajian karyawan yang terkomputerisasi sehingga dapat dihasilkan informasi yang cepat, tepat dan akurat.

b. Perancangan database untuk sistem aplikasi penggajian karyawan, sehingga penyimpanan data lebih banyak dan tidak menggunakan media kertas lagi melainkan berupa space harddisk yang terdapat pada komputer.

c. Membuat aplikasi penggajian karyawan yang mudah dipahami agar dapat digunakan oleh setiap user, baik yang memahami komputer atau tidak.

2) Diagram konteks sistem diusulkan

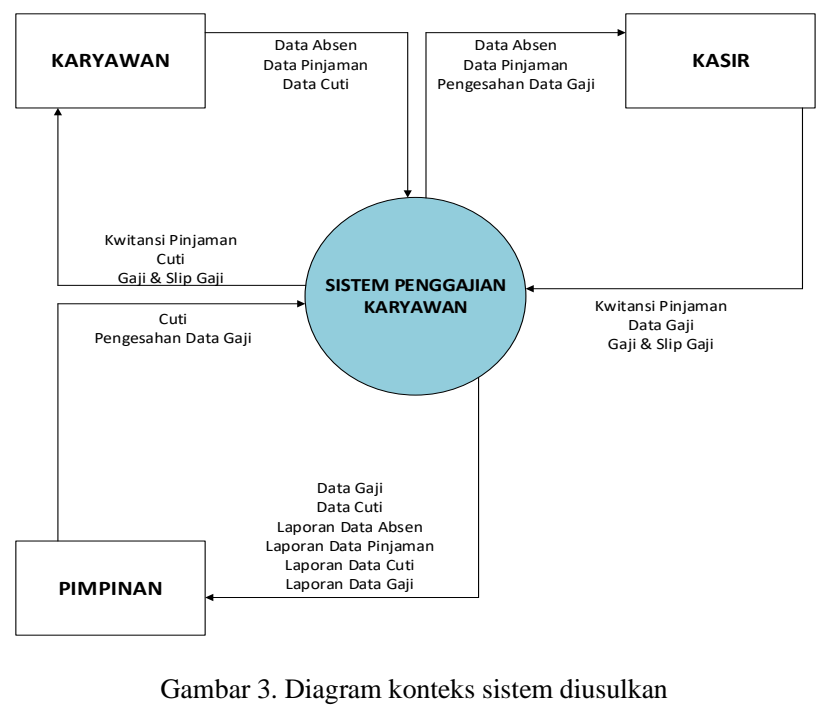

3) Diagram nol sistem yang diusulkan

Diagram ini dibuat untuk menggambarkan tahapan proses yang ada didalam diagram konteks, yang penjabarannya lebih terperinci. 


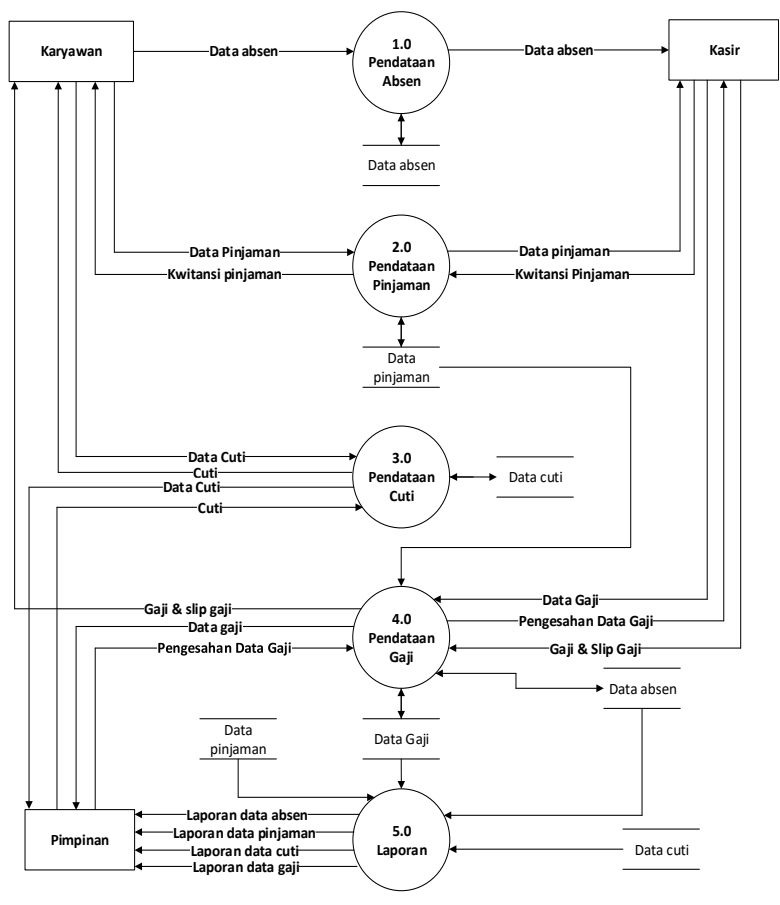

Gambar 4. Diagram nol sistem yang diusulkan

\section{4) Diagram rinci}

Diagram ini dibuat untuk menggambarkan arus data secara lebih mendetail lagi dari tahapan proses yang ada didalam diagram nol.

a) Diagram rinci level 1 proses 1

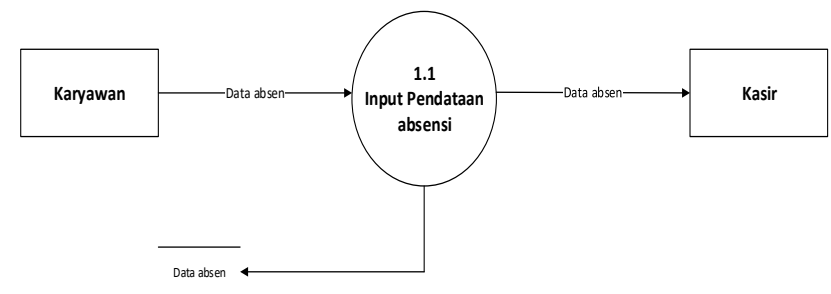

Gambar 5. Diagram rinci level 1 proses 1

b) Diagram rinci level 1 proses 2

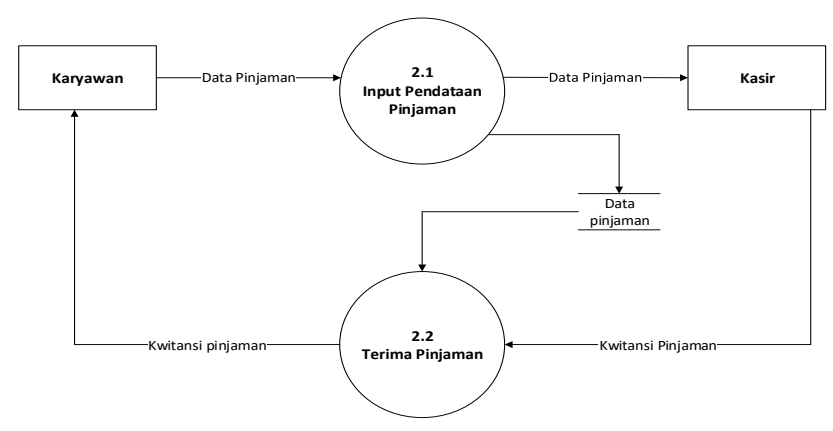

Gambar 6. Diagram rinci level 1 proses 2 c) Diagram rinci level 1 proses 3

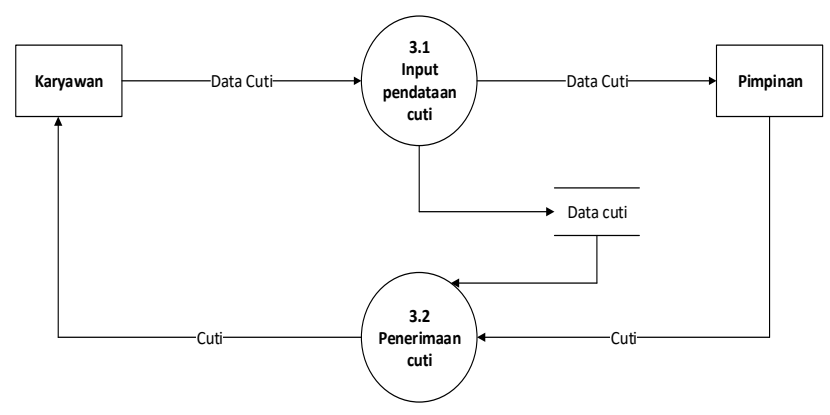

Gambar 7. Diagram rinci level 1 proses 3

d) Diagram rinci level 1 proses 4

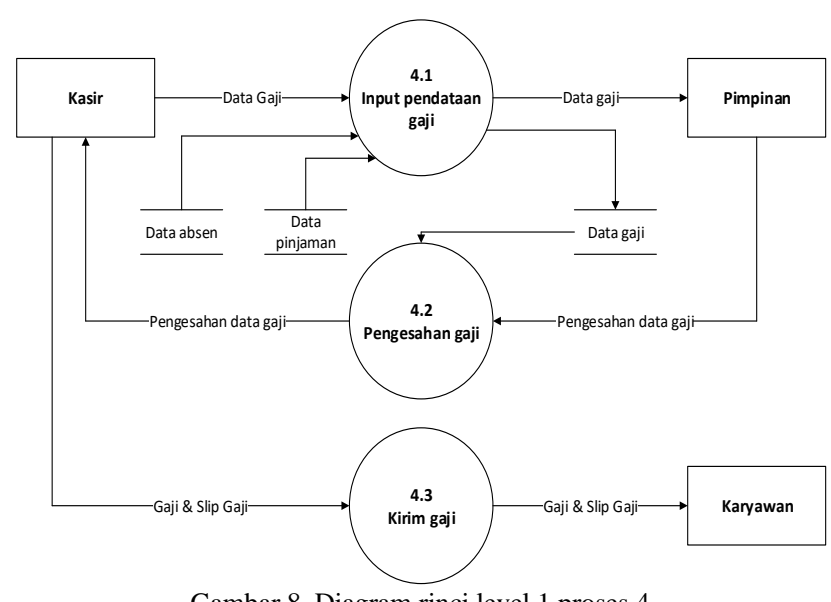

e) Diagram rinci level 1 proses 5

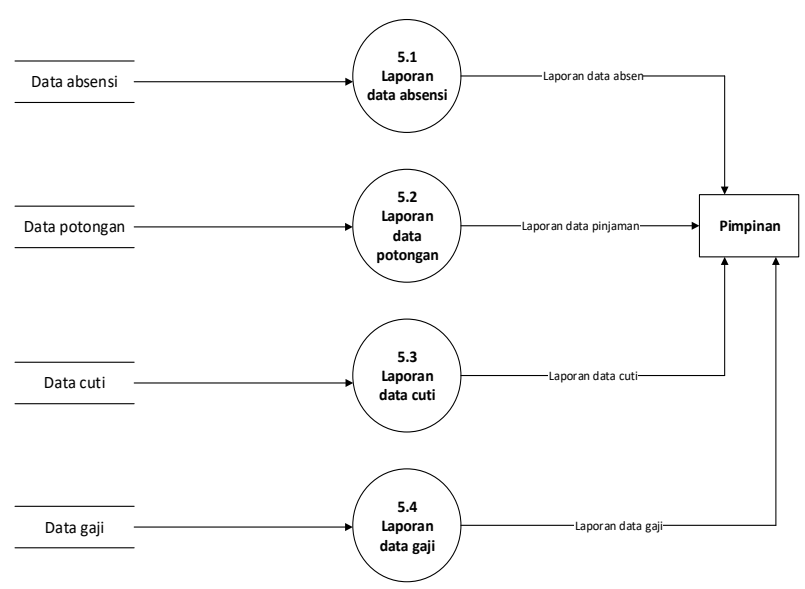

Gambar 9. Diagram rinci level 1 proses 5

\subsection{Entity Relationship Diagram (ERD)}

Digunakan untuk menyusun database agar dapat menggambarkan data yang mempunyai relasi dengan database yang akan didesain. 


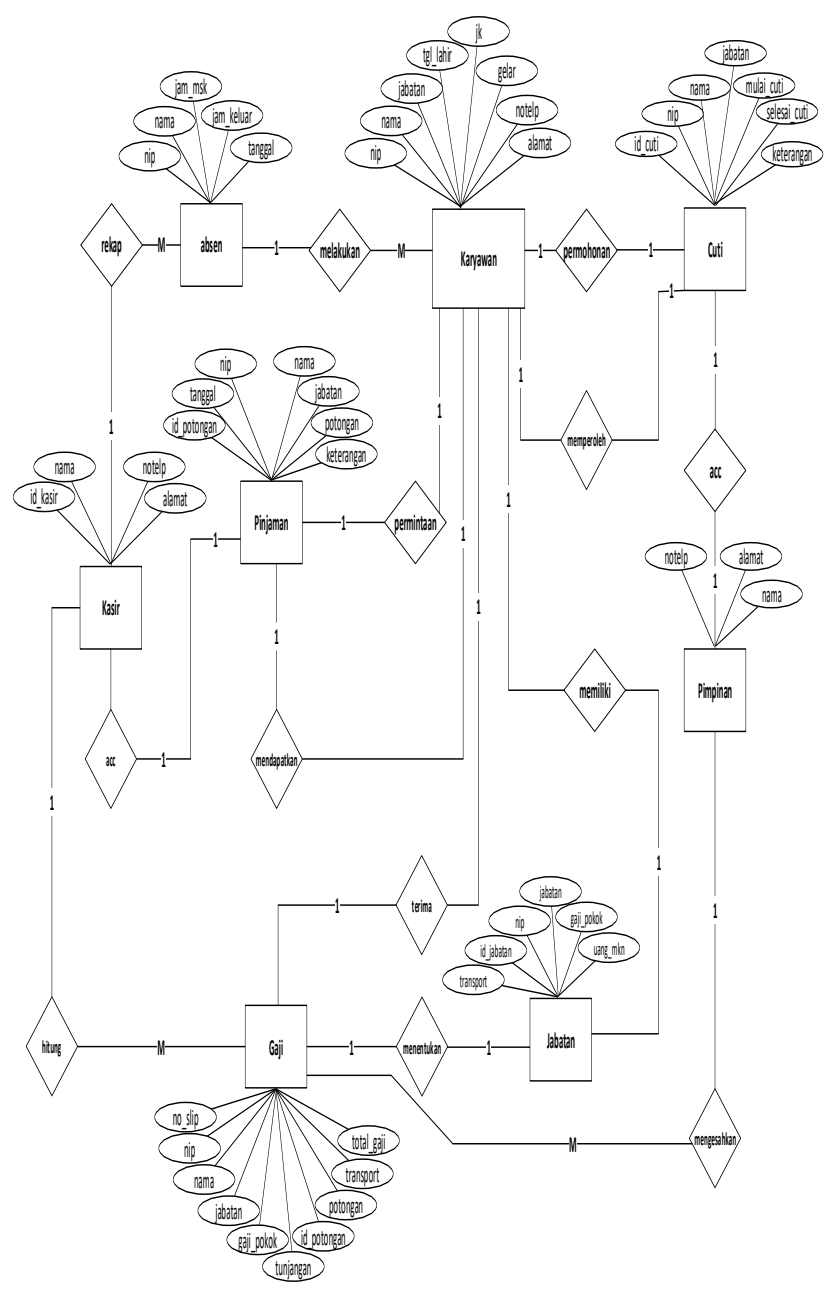

Gambar 10. Entity Relationship Diagram (ERD)

\subsection{User Interface}

1) Tampilan login

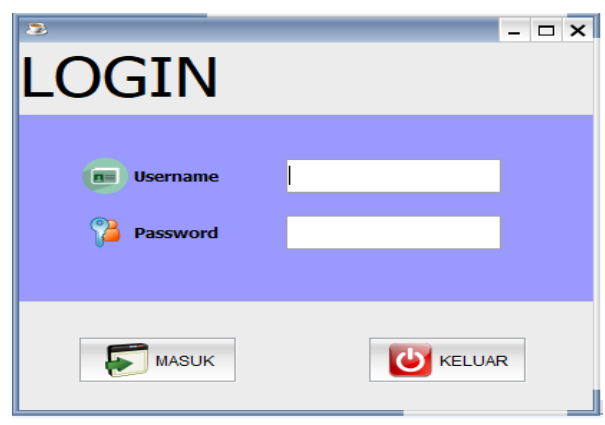

Gambar 11. Tampilan login

Tampilan di atas terdapat pada awal program. login digunakan sebagai kata kunci sebelum kita memasuki menu utama. Agar tidak ada orang dapat mengakses program ini, sehingga tetap terjaga kerahasiannya dengan baik. Apabila pengguna dapat memasukan kata kunci dengan benar maka akan masuk kedalam tampilan menu utama.
2) Tampilan menu utama

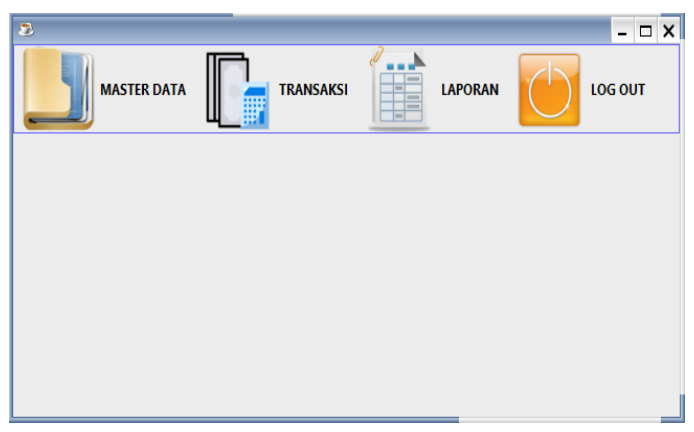

Gambar 12. Tampilan menu utama

Tampilan di atas menampilkan menu aplikasi penggajian karyawan. Pada layar utama tersedia beberapa menu yang terdiri dari master data, transaksi, laporan dan terdapat juga tombol logout.

3) Tampilan form data karyawan

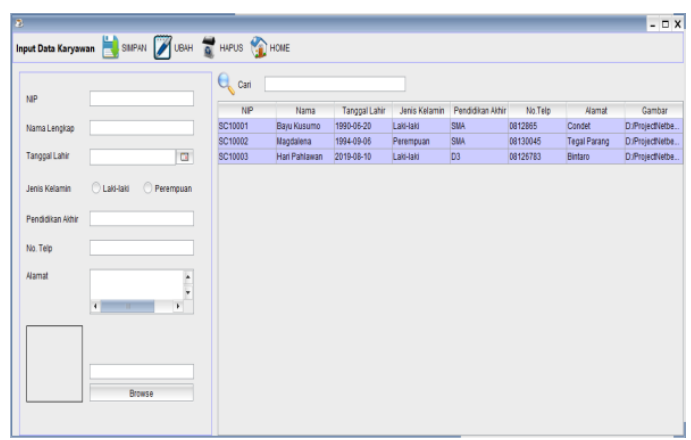

Gambar 13. Tampilan form data karyawan

Tampilan di atas merupakan tampilan form data karyawan. Form ini memiliki beberapa tombol yang terdiri tombol simpan yang berfungsi untuk menyimpan data karyawan, tombol hapus untuk menghapus data karyawan, tombol edit untuk mengedit data karyawan dan tombol menu untuk kembali ke tampilan menu utama.

4) Tampilan form data jabatan

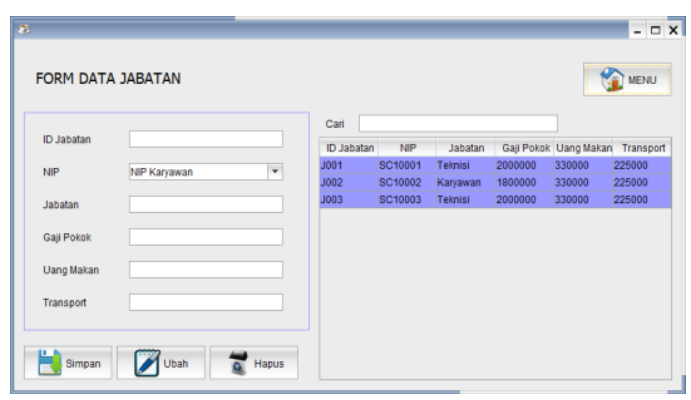

Gambar 14. Tampilan form data jabatan

Tampilan di atas merupakan tampilan form data jabatan. Form ini memiliki beberapa tombol yang terdiri tombol simpan yang berfungsi untuk menyimpan data jabatan, tombol hapus untuk menghapus data jabatan, tombol ubah untuk mengubah data jabatan dan tombol menu untuk kembali ketampilan menu utama. 
5) Tampilan form data pinjaman

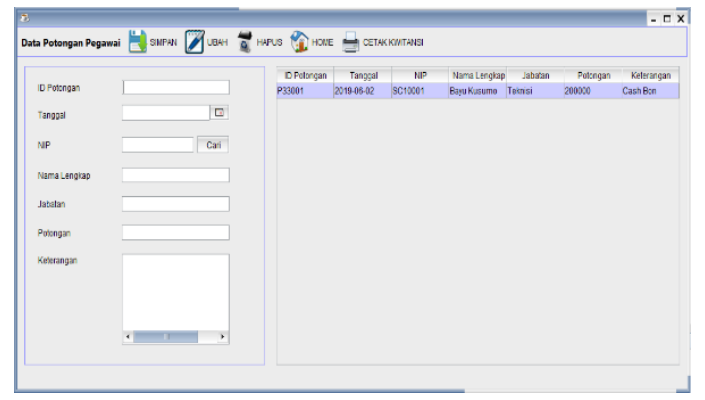

Gambar 15. Tampilan form data pinjaman

Tampilan di atas merupakan tampilan form data pinjaman. Form ini memiliki beberapa tombol yang terdiri tombol simpan yang berfungsi untuk menyimpan data pinjaman, tombol hapus untuk menghapus data pinjaman, tombol ubah untuk mengubah data pinjaman, tombol cetak untuk mencetak kwitansi pinjaman dan tombol menu untuk kembali ke tampilan menu utama.

6) Tampilan form data absensi

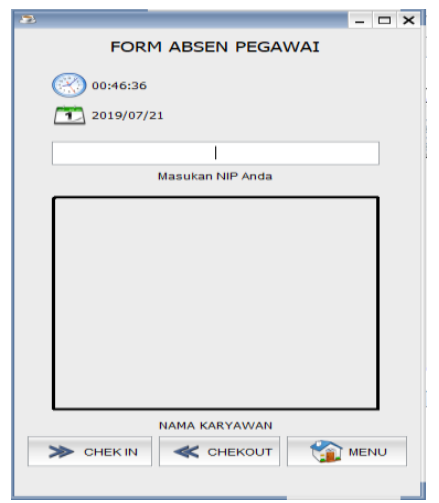

Gambar 16. Tampilan form data absensi

Tampilan di atas merupakan tampilan form absen pegawai. Form ini memiliki beberapa tombol yang terdiri tombol chek in yang berfungsi untuk mencatat data jam masuk pegawai, tombol chek out untuk mencatat jam kepulangan dan tombol menu untuk kembali ke tampilan menu utama.

7) Tampilan form data cuti

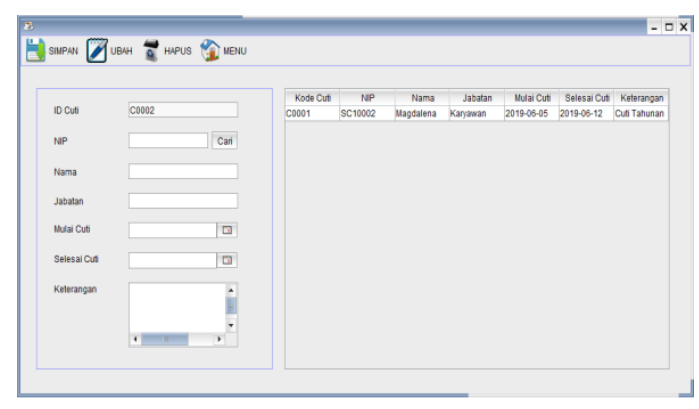

Gambar 17. Tampilan form data cuti

Tampilan di atas merupakan tampilan form data cuti. Form ini memiliki beberapa tombol yang terdiri tombol simpan yang berfungsi untuk menyimpan data cuti, tombol hapus untuk menghapus data cuti, tombol ubah untuk mengubah data cuti dan tombol menu untuk kembali ke tampilan menu utama.

8) Tampilan form data gaji

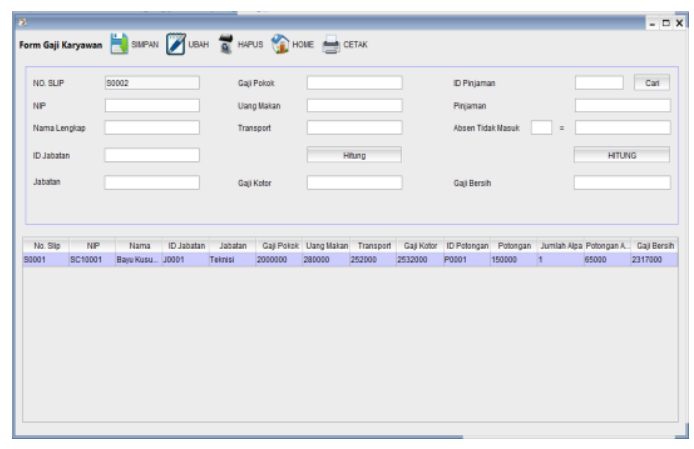

Gambar 18. Tampilan form data gaji

Tampilan di atas merupakan tampilan form data gaji. Form ini memiliki beberapa tombol yang terdiri tombol simpan yang berfungsi untuk menyimpan data gaji, tombol hapus untuk menghapus data gaji, tombol ubah untuk mengubah data gaji, tombol cetak untuk mencetak slip gaji dan tombol menu untuk kembali ke tampilan menu utama.

\section{KESIMPULAN}

Berdasarkan dari hasil perancangan tentang aplikasi penggajian karyawan yang diusulkan, maka penulis dapat menarik kesimpulan bahwa:

1) Dari analisa proses berjalan, maka dibangunlah aplikasi meliputi penggajian dan absensi karyawan pada $\mathrm{CV}$. System Comutama.

2) Dengan adanya sistem aplikasi penggajian, dimana sering terjadi human error sudah dapat dikurangi.

3) Dengan adanya aplikasi penggajian karyawan, maka saat ini pengolahan data absensi dan data penggajian karyawan di CV. System Comutama bisa dilakukan dengan lebih efektif dan efisien.

\section{DAFTAR PUSTAKA}

[1] I. Yulistiawan, N. Hidayah dan Z. Arham, "Rancang Bangun Sistem Informasi Penggajian Karyawan (Studi Kasus: Bank Pembiayaan Rakyat Syariah Harta Insan Karimah)," Studia Informatika: Jurnal Sistem Informasi, vol. 4, no. 2, pp. 1-8, 2012.

[2] Mulyadi, Sistem Akuntansi, Edisi Ketiga, Jakarta: Salemba Empat, 2013.

[3] M. T. Dangnga dan M. Ramli, "Pengaruh Gaji dan Insentif terhadap Kinerja Karyawan pada Hotel Grand Clarion di Kota Makassar," Jurnal Economix, vol. 1, no. 1, pp. 134-150, 2013.

[4] M. D. Irawan dan L. Hasni, "Sistem Penggajian Karyawan Pada LKP Grace Education Center, " Jurnal Teknologi Informasi, vol. 1, no. 2, pp. 125136, 2017.

[5] I. Ananda dan E. Zuraidah, "Perancangan Sistem Informasi Penjualan Barang Pada PT Asia Truk Pratama Jakarta," Jurnal Informatika, vol. 6, no. 2, pp. 193-200, 2019. 
[6] A. Juansyah, "Pembangunan Aplikasi Child Tracker Berbasis Assisted - Global Positioning System ( AGPS ) Dengan Platform Android," Jurnal Ilmiah Komputer dan Informatika (KOMPUTA), vol. 1, no. 1, pp. 1-8, 2015.

[7] R. Afyenni, "Perancangan Data Flow Diagram untuk Sistem Informasi Sekolah (Studi Kasus Pada SMA Pembangunan Laboratorium UNP)," Teknoif, vol. 2, no. 1, pp. 35-39, 2014.

[8] M. Witama, "Perancangan Aplikasi Pengolahan Aset Barang," Jurnal String, vol. 3, no. 3, pp. 211-219, 2019.

\section{BIODATA PENULIS}

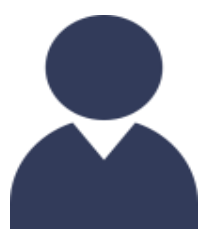

\section{Bayu Kusumo}

Lahir di Jakarta, Lulus pendidikan S1 di Universitas Indraprasta PGRI Jakarta pada Program Studi Informatika. 